\section{PENGENALAN BAHASA INGGRIS MELALUI LAGU DI TPQ AL KAUTSAR I}

Arini Hidayah', Budi Purnomo², Yunita Widiyantari ${ }^{3}$, Eka Susylowati ${ }^{4}$

1,2,3,4) Sastra Inggris, Universitas Surakarta

* Arini Hidayah

Email:ariniunsa@gmail.com

\section{Abstract}

The goal of the community service entitled Introduction to English through songs at TPQ AI Kautsar I is to introduce English vocabulary through songs to improve students' comprehension of English. English song content taught at TPQ Al Kautsar I has never been obtained. The first stage was to conduct a series of English language introduction activities for pupils using songs to train pupils at TPQ AI Kautsar. Community service increased pupils' English comprehension. TPQ Al Kautsar pupils, based on observations made by the community service team, there are indications of increased English comprehension among pupils at TPQ AI Kautsar I.

Keywords: Learning, Song, and English Vocabulary

\begin{abstract}
Abstrak
Tujuan pengabdian kepada masyarakat yang berjudul pengenalan Bahasa Inggris melalui lagu di TPQ Al Kautsar I adalah memberikan pengenalan kosakata Bahasa Inggris mealui lagu agar meningkatkan peningkatan pemahaman berbahasa Inggris pada santri TPQ Al Kautsar I. Permasalahan yang dihadapi oleh santri adalah pemahaman Bahasa Inggris adalah para santri belum pernah mendapatkan materi lagu berbahasa Inggris yang diajarkan di TPQ AI Kautsar I. Langkah yang dilakukan adalah melakukan serangkaian kegiatan pengenalan Bahasa Inggris melalui lagu kepada mahasiswa untuk memberikan pelatihan kepada santri TPQ Al Kautsar I. Kesimpulan hasil pengabdian kepada masyarakat adalah terdapat peningkatan pemahaman berbahasa Inggris pada santri TPQ Al Kautsar I. Indikasi peningkatan pemahaman berbahasa Inggris pada santri TPQ AI Kautsar I terlihat berdasarkan observasi yang dilakukan oleh tim pengabdian kepada masyarakat.

Kata Kunci: Pembelajaran, Lagu, dan Kosakata Bahasa Inggris
\end{abstract}

Received: November 06, 202 I / Accepted: November 30, 202 I / Published Online: December 20, 202 I 
PENGENALAN BAHASA INGGRIS MELALUI LAGU DI TPQ AL KAUTSAR 1

Arini Hidayah, Budi Purnomo, Yunita Widiyantari, Eka Susylowati

Volume 1, No. 3, Desember 2021 hal. 226-231

DOI Artikel: 10.46306/jub.v1i3.43

\section{PENDAHULUAN}

Pada zaman modern seperti saat ini, ada beberapa hal yang dapat memberikan dampak yang positif dan dampak yang negatif jika orang tua tidak bijak dalam megawasi penggunaan segala jenis perangkat canggih yang biasanya disebut smartphone. Penggunaan smartphone dapat menggantikan kebiasaan yang sering dilakukan oleh orang tua dengan anak, contohnya: zaman dulu anak menunggu orang tua agar dibacakan dongeng atau cerita sebelum tidur di kamar dengan bacaan cerita dongeng, pada zaman ini anak dapat mendengarkan cerita dongeng melalui smartphone dalam berbagai bahasa tanpa harus menunggu orang tua menceritakan kepada anak. Oleh karena itu, hal tersebut dapat membuat interkasi antara orang tua dan anak menurun. Interaksi kecakapan hidup sangat penting dimiliki oleh anak yang memiliki kecakapan hidup yang diharapkan dapat membantu anak dalam menghadapi segala hal di hidup mereka kelak (Pamungkas: 2014). Apalagi saat ini sedang pandemi Covid-19 yang pembelajaran awalnya luring, kemudian dirubah menjadi daring, kemudian saat pada Agustus, pembelajarann dirubah menjadi luring campur daring. Banyak anak menggunakan smartphone digunakan baik untuk pembelajaran sekolah maupun hiburan.

Pelajar dan orang tua dalam pembelajaran daring terdapat beberapa kekurangan baik yang dirasakan oleh guru. Pandemi Covid-19 yang terjadi pada tahun 2020 telah memberikan dampak yang sangat besar dalam semua bidang, khususnya pada bidang pendidikan (Hidayah, Cahyaningrum, Widiyantari, Anindhita, dan Triono: 2021). Adanya pandemi Covid-19 ini membuat proses pembelajaran berubah menjadi pembelajaran online atau daring atau jarak jauh, akan tetapi guru atau pengajar harus melakukan kewajibannya yang mana guru atau pengajar harus memastikan bahwa pelajar agar bisa memperoleh informasi atau pengetahuan (Cahyaningrum dan Baraja: 2021).

Mitra pada pengabdian masyarakat adalah TPQ Al Kautsar I yang berada di daerah Ngares, Kadireso, Teras, Boyolali. Kemampuan berbicara berbahasa Inggris pada zaman modern ini merupakan kemampuan yang wajib dimiliki oleh setiap individu, termasuk santri di TPQ AI Kautsar I. Karena terdapat banyak santri TPQ AI Kautsar I yang belum bisa mahir dalam berbicara Bahasa Inggris dan kurang dalam pengetahuan Bahasa Inggris. Ada juga santri TPQ Al Kautsar I yang malu jika berbicara berbahasa Inggris khawatir kalau dipermalukan oleh santri lain. Budaya Indonesia banyak memngajarkan Bahasa Inggris tradisional yakni pengajaran yang pusatnya guru (Masdugi: 2004). Pengajaran yang berpusat pada guru menjadi santri menjadi pendengar saja. Kemudian hasilnya santri menjadi pasif dalam pembelajaran dan santri tidak bisa mengungkapkan kemampuan berbicara Bahasa Inggris. Kegiatan belajar mengajar santri di TPQ AI Kautsar I belum pernah diberi pelajaran agama yang mengandung pelajaran Bahasa Inggris. Agar membuat santri TPQ AI Kautsar I lebih percaya diri dalam berbicara berbahasa Inggris.

Berdasarkan latar belakang permasalahan tersebut kegiatan abdimas ini bertujuan memberikan pelatihan kegiatan pengenalan bahasa Inggris melalui lagu kepada santri TPQ AI Kautsar I. Kegiatan 
PENGENALAN BAHASA INGGRIS MELALUI LAGU DI TPQ AL KAUTSAR 1

Arini Hidayah, Budi Purnomo, Yunita Widiyantari, Eka Susylowati

Volume 1, No. 3, Desember 2021 hal. 226-231

DOI Artikel: 10.46306/jub.v1i3.43

abdimas ini yang berisi diharapkan mampu meningkatkan kemampuan berbahasa Inggris kepada santri TPQ Al Kautsar I.

\section{METODE PENGABDIAN}

Metodologi yang diterapkan dalam pelaksanaan pengabdian kepada masyarakat dalam pembelajaran Bahasa Inggris melalui lagu di TPQ AI Kautsar I adalah sebagai berikut:

\section{Observasi}

Dalam melakukan pengamatan permasalahan dalam pengabdian kepada masyarakat ini menggunakan metode observasi yakni agar mendapatkan gambaran atau latar belakang masalah yang tepat dalam hubungannya dengan kondisi dan lokasi (Ristekdikti: 2018). Tim pengabdian kepada masyarakat membutuhkan beberapa waktu dalam proses pengamatan gambaran masalah, kondisi, lokasi tempat perencanaan, dan perencanaan pembelajaran dalam pengabdian kepada masyarakat selama I hari pada hari Selasa tanggal 2 November 202I, yang mana pada hari Jumat tersebut para santri melakukan kegiatan seperti biasa di TPQ AI Kautsar I.

\section{Proses Pelaksanaan}

Pelaksanaan pengenalan pelajaran Bahasa Inggris kepada santri di TPQ Al Kautsar I dilakukan pada sekali pertemuan dengan waktu I jam pada hari Jumat pada tanggal 5 November 202 I yang dilakukan oleh penulis pengabdian kepada masyarakat. Langkah pertama dalam pembelajaran berbahasa Inggris melalui lagu kepada santri di TPQ Al Kautsar I yakni tim pengabdian kepada masyarakat memberikan pengenalan santri tentang lagu-lagu berbahasa Inggris. Langkah kedua mengajak para santri yang masih pelajar berinteraksi langsung dengan tim pengabdian kepada masyarakat langsung dengan mengajak santri mempraktekkan langsung lagulagu berbahasa Inggris yang telah dipelajari di tahap pertama. Bahan materi pengenalan lagu berbahasa Inggris yang digunakan untuk bahan pengenalan berbahasa Inggris dalam pengabdian kepada masyarakat berupa lagu Islam yang berbahasa Inggris seperti lagu-lagu Islami. Pengenalan kosakata berbahasa Inggris melalui lagu kepada santri, tim pengabdian kepada masyarakat telah menggunakan fungsi berbahasa Inggris dalam hal komunikasi dengan menggunakan latihan berpasangan atau berkelompok antara tim pengabdian kepada masyarakat dengan siswa (Tsani, Aniuranti, \& Budiman: 202I). Lagu-lagu Islami berbahasa (Zain: 20I2) yang digunakan dalam materi ajar yang digunakan antara lain: InsyaAllah, Always Be There, Palestine Will Be Free, Thank You Allah, The Choosen One, For the Rest of My Life, Hold My Hand, Awaken, Subhana Allah, dan Open Your Eyes. 
PENGENALAN BAHASA INGGRIS MELALUI LAGU DI TPQ AL KAUTSAR 1

Arini Hidayah, Budi Purnomo, Yunita Widiyantari, Eka Susylowati

Volume 1, No. 3, Desember 2021 hal. 226-231

DOI Artikel: 10.46306/jub.v1i3.43

\section{PELAKSANAAN DAN PEMBAHASAN}

Program pengabdian kepada masyarakat melalui pengenalan berbahasa Inggris melalui lagu Islami yang berbahasa Inggris dilakukan di TPQ AI Kautsar I yang dilaksanakan pada tanggal 5 November 202 I pada pukul 16.00 - 17.00 WIB. Terdapat 15 santri yang mengikuti pengenalan berbahasa Inggris melalui lagu Islami yang berbahasa Inggris. Para santri yang mengikuti pengenalan berbahasa Inggris melalui lagu Islami yang berbahasa Inggris bertinggal di Ngares, Kadireso, Teras, Boyolali.

Evalusi keberhasilan program pengabdian kepada masyarakat dalam pengenalan berbahasa Inggris melalui lagu Islami yang berbahasa Inggris yang dilakukan di TPQ AI Kautsar I bisa diambil pada evaluasi yang dilakukan. Evaluasi keberhasilan masyarakat dalam pengenalan berbahasa Inggris melalui lagu Islami yang berbahasa Inggris yang dilakukan di TPQ AI Kautsar I antara lain: I) Santri dapat meningkatkan kosakata Bahasa Inggris melalui materi lagu-lagu yang telah diajarkan, 2) Adanya kesinambungan antara materi ajar yakni lagu berbahasa Inggris dalam kehidupan sehari-hari dan kebutuhan santri dalam pelajaran Islami, 3) Penggunaan pengenalan materi melalui lagu berbahasa Inggris dengan santri telah sesuai kondisi, 4) Santri diberikan tes oleh tim pengabdian kepada masyarakat untuk mengetahui perkembangan kemampuan menyanyikan lagu berbahasa Inggris dan memahami maknanya dalam isi lagu.

Selama proses pengenalan berbahasa Inggris melalui lagu Islami yang berbahasa Inggris yang dilakukan di TPQ AI Kautsar I, para santri terlihat sangat semangat dalam memahami makna lagu Islami yang berbahasa Inggris dan mempraktekkan lagu Islami yang berbahasa Inggris kepada tim pengabdian kepada masyarakat. Santri harus memahami makna isi lagu Islami berbahasa Inggris dahulu, baru santri berlatih menyani lagu Islami berbahasa Inggris supaya lancar dalam mempraktekkan materi dari tim pengabdian kepada masyarakat.

Situasi dan kondisi dalam kegiatan pengabdian kepada masyarakat memberikan indikator kecapaian kesuksesan dalam pengenalan berbahasa Inggris melalui lagu Islami yang berbahasa Inggris yang dilakukan di TPQ AI Kautsar I karena santri dapat memahami makna isi lagu Islami berbahasa Inggris dahulu serta mempraktekkan materi ajar sudah sesuai dengan yang dibutuhkan santri. Oleh karena itu santri dapat memahami materi ajar dan dapat mempraktekkan materi lagu Islami berbahasa Inggris dengan baik dari tim pengabdian kepada masyarakat. 


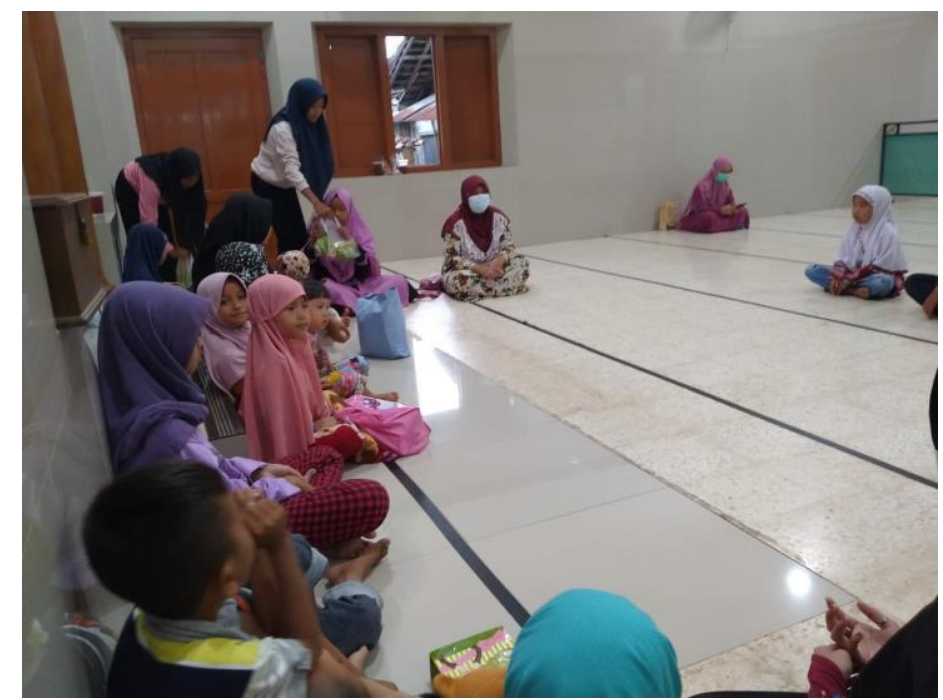

Gambar I: Pembukaan Kegiatan Pengenalan Berbahasa Inggris Melalui Lagu Islami di TPQ AI Kautsar I.

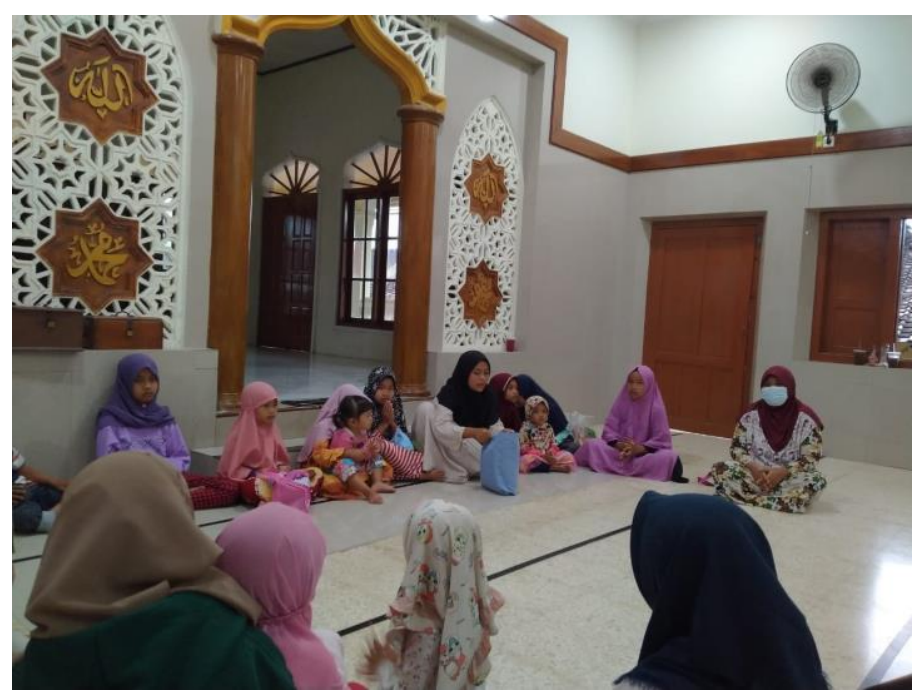

Gambar 2: Penutupan Kegiatan Kegiatan Pengenalan Berbahasa Inggris Melalui Lagu Islami di TPQ AI Kautsar I.

\section{KESIMPULAN DAN SARAN}

Kegiatan program pengabdian kepada masyarakat dalam pengenalan berbahasa Inggris melalui lagu Islami yang berbahasa Inggris yang dilakukan di TPQ AI Kautsar I dapat disimpulkan bahwa:

I) Pengenalan berbahasa Inggris melalui lagu Islami yang berbahasa Inggris yang dilakukan di TPQ AI Kautsar I membutuhkan kemampuan berbahasa Inggris. Tim pengabdian kepada masyarakat berusaha mengajak santri agar tertarik supaya ikut kegiatan dalam memahami dan praktik bernyanyi lagu Islami berbahasa Inggris

2) Untuk mengenali psikologis santri dibutuhkan dalam mengajak santri agar mengikuti bernyanyi lagu Islami berbahasa Inggris 
PENGENALAN BAHASA INGGRIS MELALUI LAGU DI TPQ AL KAUTSAR 1

Arini Hidayah, Budi Purnomo, Yunita Widiyantari, Eka Susylowati

Volume 1, No. 3, Desember 2021 hal. 226-231

DOI Artikel: 10.46306/jub.v1i3.43

3) Hambatan dalam pengenalan berbahasa Inggris melalui lagu Islami yang berbahasa Inggris yang dilakukan di TPQ Al Kautsar I adalah persiapan waktu dan bahan ajar. Tim pengabdian kepada masyarakat berusaha membuat waktu yang sesuai dengan jadwal santri di TPQ AI Kautsar I agar pada saat program pengabdian kepada masyarakat waktunya tepat dalam memberikan pelajaran kepada santri. Materi ajar yang diberikan ke santri disesuai dengan tujuan program pengabdian kepada masyarakat.

Dengan melalui kegiatan pengabdian kepada masyarakat, diharapkan santri dapat mempunyai tambahan ilmu pengetahuan dalam meningkatkan kosakata Bahasa Inggris sehingga santri mendapatkan kesenangan dalam memperkaya ilmu tanpa merasa kesulitan dalam menyerap pelajaran yang telah disampaikan oleh tim pengabdian kepada masyarakat.

\section{UCAPAN TERIMA KASIH}

Kami mengucapkan terima kasih kepada TPQ Al Kautsar I yang telah memberikan dukungan sebagai tempat kami dalam melaksanakan kegiatan pengabdian kepada masyarakat. Terima kasih kepada LP2M Universitas Surakarta yang telah memberikan izin kepada kami sehingga dapat melaksanakan kegiatan pengabdian kepada masyarakat dengan lancar. Terima kasih kepada Civitas Akademika Program Studi Sastra Inggris Fakultas Bahasa dan Sastra yang telah mendukung dalam pelaksanaan pengabdian kepada masyarakat.

\section{DAFTAR PUSTAKA}

Cahyaningrum, Ika, Oktaria \& Baraja, Abdillah. (202I). Workshop Pengembangan Media Pembelajaran Dan Bahasa Inggris Berbasis Teknologi Informatika Di Era Pandemi Bagi Guru Sdit Al Falaah Simo. Jubaedah : Jurnal Pengabdian dan Edukasi Sekolah, Volume I, No. I, April 202I hal. 37-43.

Direktorat Riset dan Pengabdian Masyarakat Direktorat Jenderal Penguatan Riset dan Pengembangan Kementerian Riset, Teknologi, dan Pendidikan Tinggi. (2018). Panduan Penilaian Kinerja Pengabdian Kepada Masyarakat Di Perguruan Tinggi. Jakarta: Direktorat Riset dan Pengabdian Masyarakat, Direktorat Jenderal Penguatan Riset dan Pengembangan Kementerian Riset, Teknologi, dan Pendidikan Tinggi.

Hidayah, A; Cahyaningrum, I, O; Widiyantari, Y; Anindhita, W, K; Sudalyo, R, A, T. (202I). Pembelajaran Percakapan Berbahasa Inggris Untuk Siswa Sekolah Melalui Siaran Radio Karysma Fm Pada Pandemi Covid19. Jubaedah: Jurnal Pengabdian dan Edukasi Sekolah, Volume. I, No. 2, Agustus 202I hal. I72-I77.

Masduki. (2004). Menjadi Broadcaster Profesional. Yogyakarta: PT LKiS Pelangi Aksara

Pamungkas, H, W. (2014). Interaksi Orang Tua Dengan Anak Dalam Menghadapi Teknologi Komunikasi Internet. Thesis: Magister IImu Sosial Fakultas IImu Sosial dan IImu Politik Universitas Tanjungpura Pontianak.

Tsani, M, H, N, Aniuranti, A, Budiman, A. (202I). Pelatihan English Conversation Bagi Tenaga Pendidik Di Universitas Nahdlatul Ulama Purwokerto. Jubaedah: Jurnal Pengabdian dan Edukasi Sekolah, Volume. I, No. 2, Agustus 202I hal. 156-164.

Zain, M. (2012). Thank You Allah Album. Swedia: Awakening Records. 